\title{
Characterization of Dutch porcine Serpulina (Treponema) isolates by restriction endonuclease analysis and DNA hybridization
}

\author{
Agnes A. H. M. ter Huurne, ${ }^{*}$ Marina van Houten, Marcel B. H. Koopman, \\ BERNARD A. M. VAN DER ZeIJST and WiM GaAsTra \\ Institute of Infectious Diseases and Immunology, Department of Bacteriology, Faculty of Veterinary Medicine, \\ University of Utrecht, Yalelaan 1, PO Box 80.165, 3508 TD Utrecht, The Netherlands
}

(Received 17 February 1992; revised 13 May 1992; accepted I June 1992)

\begin{abstract}
Genomes of 55 Dutch porcine Serpulina (Treponema) hyodysenteriae and non-pathogenic Serpulina isolates were characterized by restriction endonuclease analysis (REA) and DNA hybridization. The Dutch porcine isolates were compared with American Type Culture Collection (ATCC) strains of S. hyodysenteriae and S. innocens and isolates of $S$. hyodysenteriae with known serotypes (reference strains). REA of the Dutch $S$. hyodysenteriae isolates resulted in two main patterns, while the non-pathogenic isolates had many distinct REA patterns, all different from the $S$. hyodysenteriae strains. The $S$. hyodysenteriae reference strains all had distinct $R E A$ patterns, different from the Dutch strains. Upon Southern hybridization with a $S$. hyodysenteriae DNA fragment encoding a flagellar protein, all $S$. hyodysenteriae strains could be divided in two groups. The non-pathogenic Serpulina strains had many distinct hybridization patterns and hybridized less intensely. Upon hybridization with a S. hyodysenteriae DNA fragment encoding a haemolysin, DNA of all $S$. hyodysenteriae strains reacted in the same band. DNA of non-pathogenic Dutch Serpulina strains and $S$. innocens did not hybridize. It was concluded that there are two main genotypes of $S$. hyodysenteriae in the Netherlands. This could be of importance for recombinant DNA vaccine development.
\end{abstract}

\section{Introduction}

Serpulina (Treponema) hyodysenteriae, an anaerobic $\beta$ haemolytic spirochaete, is the major aetiologic agent of swine dysentery, a diarrhoeal disease of swine characterized by inflammation, excess mucus production and necrosis of the large intestine. This leads to haemorrhage, dehydration, weight loss and eventually death (Harris et al., 1972; Taylor \& Alexander, 1971).

$S$. hyodysenteriae is differentiated from the nonpathogenic, weakly $\beta$-haemolytic Serpulina (Treponema) innocens by strong $\beta$-haemolysis on blood agar plates or by enteropathogenicity testing in pigs or mice (Kinyon \& Harris, 1979; Kinyon et al., 1977).

Control of swine dysentery can be achieved by drug medication (Olson, 1986) or vaccination and the latter should be feasible since natural immunity in pigs against the disease has been demonstrated in convalescent animals (Joens et al., 1979). The immunity which developed in pigs was partially serotype specific (Joens et

\footnotetext{
* Author for correspondence. Tel. 30 534987/534888; fax 30540784.

Abbreviations: REA, restriction endonuclease analysis.
}

al., 1983). Attempts to induce immunity to swine dysentery with whole-cell preparations had limited success and resulted only in partial protection (Fernie et al., 1983; Glock et al., 1978; Lysons \& Burrows, 1989).

Thus it might be necessary to develop a recombinant DNA vaccine, containing proteins with epitopes common to all types. Since flagella and haemolysin(s) are considered to be important virulence factors of $S$. hyodysenteriae (Koopman et al., 1992; Muir et al., 1992; Boyden et al., 1989; Lysons et al., 1991, Huurne et al., 1992), we focused on these proteins. Genes encoding some of these proteins have been cloned (Koopman et al., 1992; Muir et al., 1992).

For the development of a recombinant DNA vaccine for swine dysentery, we are interested in the prevalence of pathogenic clones of $S$. hyodysenteriae in the Netherlands. It was our objective to study the genetic diversity of porcine Serpulina isolates with special emphasis on genes encoding flagellar proteins and haemolysin.

Genotyping by restriction endonuclease analysis (REA) and DNA hybridization has been useful for a number of bacterial species since it not only differentiated between strains but also demonstrated previously 
Table 1. Haemolysis, hybridization patterns with Fla and Tly probes and REA patterns of porcine Serpulina strains

Tly, DNA fragment from a haemolytic clone of $S$. hyodysenteriae; Fla, DNA fragment of $S$. hyodysenteriae coding for a $43 \mathrm{kD}$ flagellar protein.

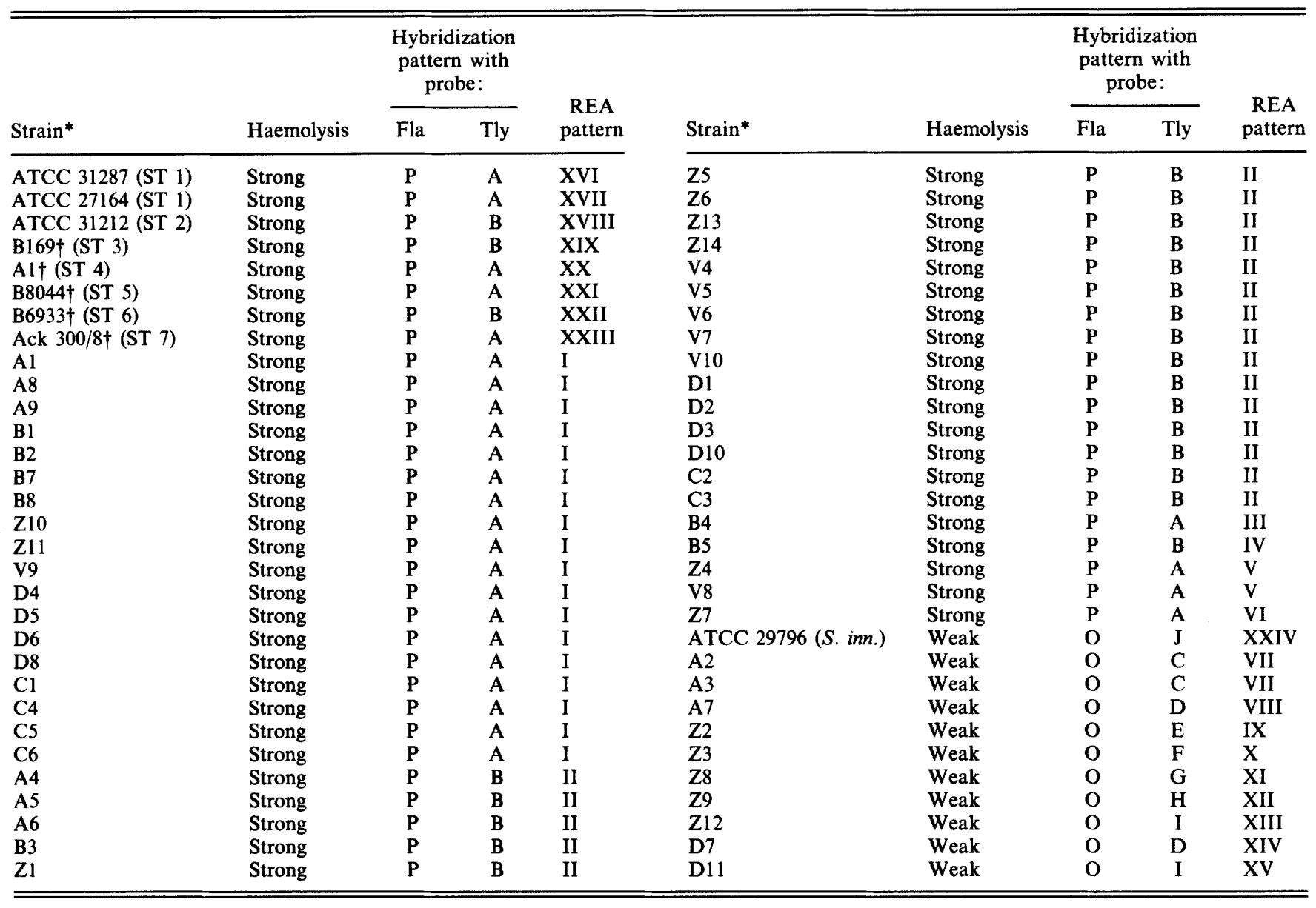

* Strains B1-8, Z1-9, V4-9 and D1-11, isolates from samples from Animal Health Centres (AHC) Boxtel, Zwolle, Velp and Drachten respectively; A1-8 and $\mathrm{Cl}-6$, isolates received from AHC Boxtel and Central Veterinary Institute Lelystad, respectively: ATCC, American Type Culture Collection; †, strains with known serotypes obtained through Dr S. Muir from L. A. Joens; ST.1-7, S. hyodysenteriae serotypes 1-7; S. inn., S. innocens.

unknown genetic relationships (Collins et al., 1990; Ellis et al., 1991; van Eys et al., 1991; LeFebvre et al., 1989; Thiermann et al., 1986).

We have characterized Serpulina isolates obtained from pigs from various regions in the Netherlands by REA and DNA hybridization. REA and DNA hybridization patterns of these Serpulina isolates were compared with those of Serpulina strains of the American Type Culture Collection (ATCC) and several isolates with known serotypes.

\section{Methods}

Serpulina isolates. Fifty-five faecal and colon samples, positive in the unabsorbed, direct immunofluorescence assay (IFA) (Smit \& Jongerius, 1982), were received from the Dutch Regional Animal Health Centres (AHC) at Drachten, Zwolle, Velp and Boxtel. All samples came from diseased pigs from different farms. For primary isolation all samples were streaked on Trypticase soy agar (TSA; BBL
Microbiology Systems) supplemented with $5 \%$ (v/v) sheep blood (TSAB) and $400 \mu \mathrm{g}$ spectinomycin $\mathrm{ml}^{-1}$ (Songer et al., 1976) and on the improved selective medium of TSAB according to Kunkle \& Kinyon (1988). For subculturing TSAB was used. Incubation took place under anaerobic conditions (Gas-Pak jar) at $37^{\circ} \mathrm{C}$ for $5 \mathrm{~d}$. The gaseous environment comprised $\mathrm{CO}_{2}$ and $\mathrm{H}_{2}$ and was produced using a gas generator envelope with palladium catalyst (BBL). A number of Dutch porcine Serpulina strains previously isolated at the AHC at Boxtel (nine isolates) and the Central Veterinary Institute (CVI) at Lelystad (six isolates) were also examined. Three $S$. hyodysenteriae isolates [B234T ATCC 31287, B78 ${ }^{\mathrm{T}}$ ATCC 27164 (both serotype 1) and B204 ${ }^{\mathrm{T}}$ ATCC 31212 (serotype 2)] and one $S$. innocens isolate (ATCC 29796) were obtained from the American Type Culture Collection. DNA of isolates with known serotypes was received from Dr S. Muir: B169 (serotype 3), Al (serotype 4), B8044 (serotype 5), B6933 (serotype 6) and Ack 300/8 (serotype 7) (Mapother \&-Joens, 1985). All isolates were differentiated as strongly or weakly $\beta$-haemolytic by the haemolytic pattern on TSAB (Kinyon \& Harris, 1979).

Isolation of chromosomal DNA. For the isolation of chromosomal DNA, all isolates were grown on TSAB. Approximately $5 \times 10^{9}$ treponemes were harvested and washed in phosphate-buffered saline 


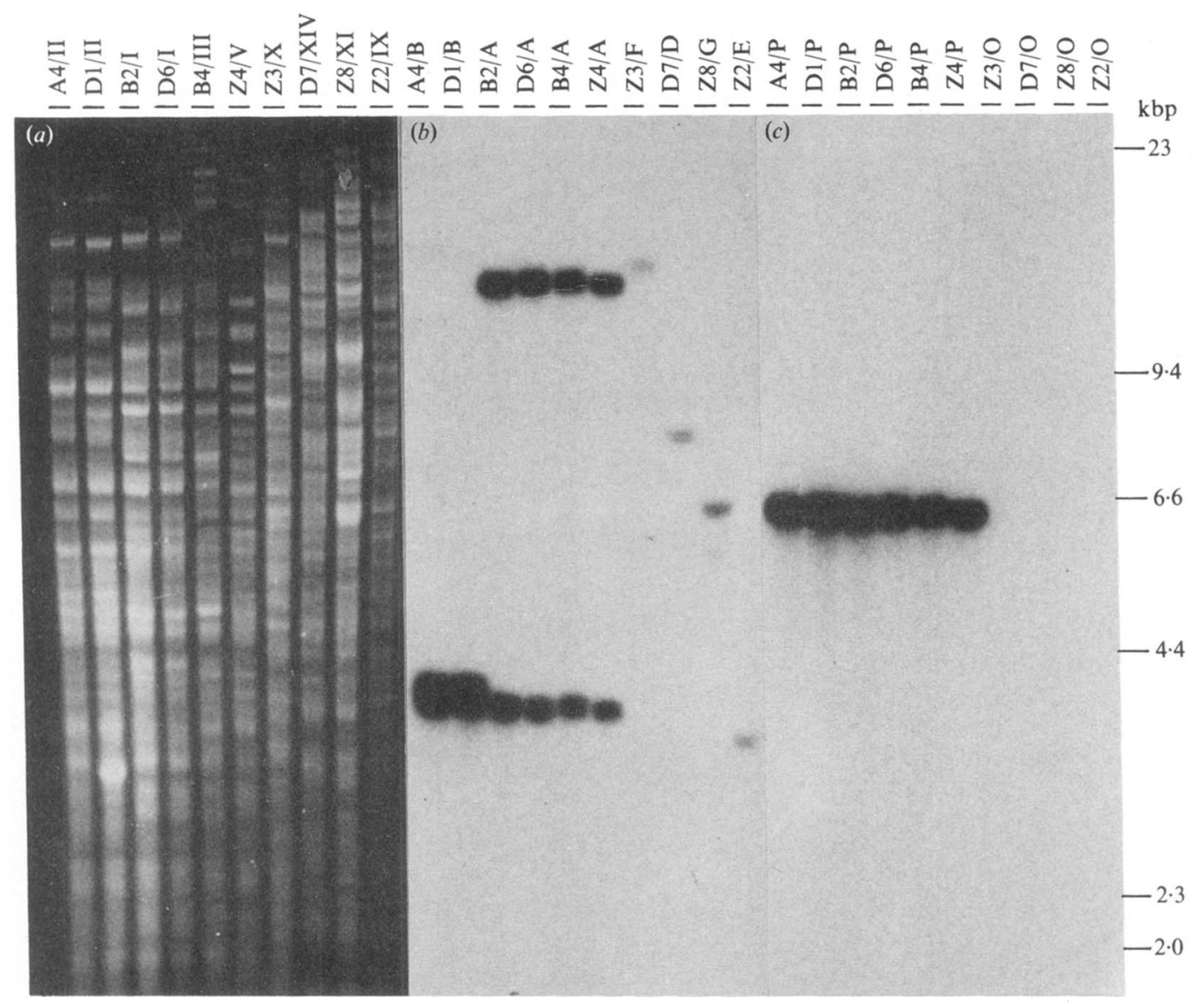

Fig. 1. REA and Southern hybridization of TaqI digests of DNA of Dutch porcine Serpulina isolates. Lanes 1-6 in each of $(a)$, (b) and (c) contain DNA of $S$. hyodysenteriae strains, while lanes 7-10 contain DNA of non-pathogenic strains. Numbers and letters at the top of each lane refer to the isolates/REA or hybridization patterns listed in Table 1. (a) Gel electrophoresis of TaqI digests of the isolates. (b) Southern hybridization of the same gel with Fla probe. (c) Southern hybridization of the same gel with Tly probe. Molecular size markers are indicated on the right.

(PBS) pH 7-4. Chromosomal DNA was isolated by standard methods (Sambrook et al., 1989).

Restriction endonuclease analysis. The restriction endonuclease TaqI (BRL) was selected for this study since it yielded clear, well distinguished bands. Approximately $2 \mu \mathrm{g}$ chromosomal DNA was digested with $10 \mathrm{U} \mathrm{TaqI}$ and the fragments were separated in a $0.7 \%$ agarose gel in TAE buffer (Tris/acetate/EDTA) at $2 \mathrm{~V} \mathrm{~cm}^{-1}$ for $16 \mathrm{~h}$ (Sambrook et al., 1989). Subsequently, the gels were stained with ethidium bromide and photographed under short-wavelength UV light.

DNA hybridization. Fragments were transferred to a Hybond-N membrane (Amersham) by Southern blotting using standard procedures (Sambrook et al., 1989). An S. hyodysenteriae DNA fragment of approximately $2.2 \mathrm{kbp}$ coding for a $43 \mathrm{kDa}$ flagellar protein (Fla probe) (Koopman et al., 1992), and a $1.4 \mathrm{kbp}$ DNA fragment containing the $t l y$ gene encoding a $S$. hyodysenteriae haemolysin (Tly probe) (Muir $e t$ al., 1992) were radiolabelled and used as probes (Sambrook et al., 1989). Filters were prehybridized for $8 \mathrm{~h}$ at $42^{\circ} \mathrm{C}$ in a prehybridization mix with $50 \%(\mathrm{v} / \mathrm{v})$ formamide and salmon sperm DNA. Filters were hybridized for $16 \mathrm{~h}$ at $42{ }^{\circ} \mathrm{C}$ in the same buffer and washed three times in $2 \times \operatorname{SSPE}\left(20 \mathrm{mM}-\mathrm{NaH}_{2} \mathrm{PO}_{4} .360 \mathrm{~mm}-\mathrm{NaCl}, 2 \mathrm{mM}-\mathrm{EDTA}\right)+0.1 \%$ SDS at $42^{\circ} \mathrm{C}$ for $15 \mathrm{~min}$ (Sambrook et al., 1989). The blots were dried and exposed to X-ray film.

\section{Results}

\section{Serpulina isolates}

From the 55 samples received, 38 Serpulina strains were isolated. A total of 43 Dutch $S$. hyodysenteriae and 10 Dutch non-pathogenic porcine spirochaetal (referred to below as non-pathogenic Serpulina) strains were examined. They were compared with eight $S$. hyodysenteriae reference strains and with $S$. innocens ATCC 29796.

\section{Restriction endonuclease analysis}

Although the $43 S$. hyodysenteriae Dutch porcine strains had six different REA patterns, most strains fell within pattern I or II : I (18 strains), II (20 strains), III (1 strain), IV (1 strain), V ( 2 strains) and VI (1 strain). The 10 nonpathogenic Dutch Serpulina strains had a greater variation and all differed from the $S$. hyodysenteriae strains: patterns VII to XV (only 2 strains had identical REA patterns). The $S$. hyodysenteriae reference strains 


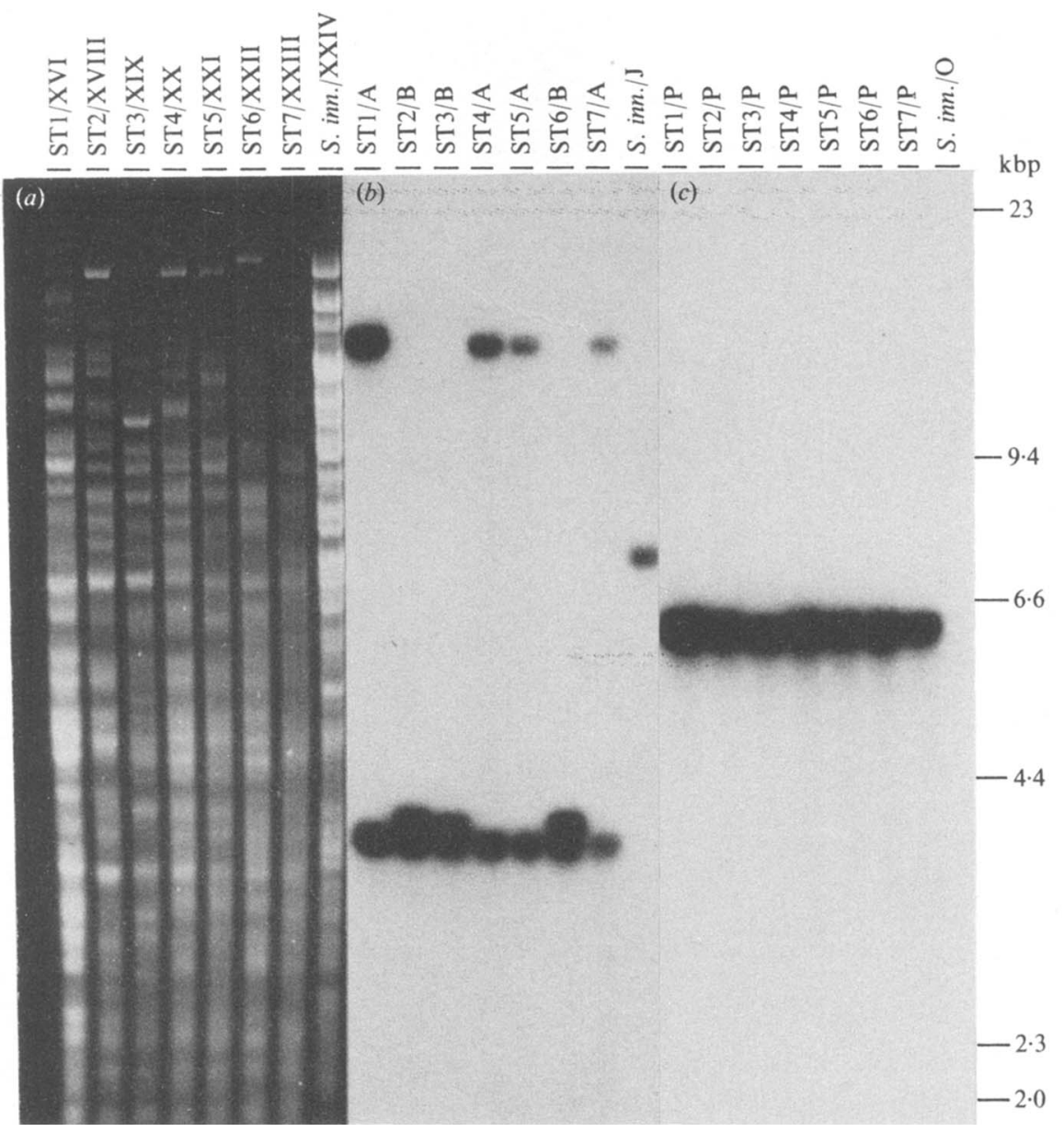

Fig. 2. REA and Southern hybridization of Taql digests of DNA of S. hyodysenteriae and S. innocens reference strains. Serotypes (ST) and $S$. innocens $(S$. inn.) are indicated at the top of each lane. The strains representing the serotypes are listed in Table 1. For serotype 1 , DNA of strain ATCC 31287 was used. Letters at the top of each lane refer to the REA or hybridization patterns, also listed in Table 1. (a) Gel electrophoresis of TaqI digests of the isolates. (b) Southern hybridization of the same gel with Fla probe. (c) Southern hybridization of the same gel with Tly probe. Molecular size markers are indicated on the right.

all had different REA patterns: XVI to XXIII. $S$. innocens had REA pattern XXIV.

REA patterns of all strains are listed in Table 1. Representative REA patterns are shown in Figs $1(a)$ and $2(a)$.

\section{DNA hybridization}

Hybridization with the Fla probe was carried out on DNA from all strains. The 18 strains with REA pattern I and 9 strains with other REA patterns hybridized strongly with fragments of approximately 4 and $14 \mathrm{kbp}$ : pattern $\mathrm{A}$. The 20 strains with REA pattern II and 4 strains with other REA patterns hybridized strongly with fragments of approximately 4 and $4.2 \mathrm{kbp}$ : pattern $B$.

Hybridization of the DNA from the non-pathogenic Dutch Serpulina strains with the Fla probe was less intense and at different fragments : 2 strains with $3 \cdot 1 \mathrm{kbp}$ (pattern C); 2 strains with $8.3 \mathrm{kbp}$ (pattern D); 1 strain with $3.7 \mathrm{kbp}$ (pattern E); 1 strain with $15 \mathrm{kbp}$ (pattern F); 1 strain with $6.5 \mathrm{kbp}$ (pattern G); 1 strain with 1.8 $\mathrm{kbp}$ (pattern $\mathrm{H}$ ); and 2 strains with $8.7 \mathrm{kbp}$ (pattern I). $S$. innocens hybridized, also less intensely, with a fragment of $7.2 \mathrm{kbp}$ (pattern $\mathbf{J}$ ).

Hybridization patterns with the Fla probe are listed in Table 1. Examples of these patterns are shown in Figs $1(b)$ and $2(b)$.

Upon hybridization with the Tly probe, all $S$. hyodysenteriae Dutch and reference strains hybridized with a strong band at approximately $6.5 \mathrm{kbp}$ : pattern $P$. The non-pathogenic Dutch Serpulina strains and $S$. innocens did not hybridize with Tly: pattern $\mathrm{O}$.

Hybridization patterns with the Tly probe are listed in Table 1. Examples of these patterns are shown in Figs $1(c)$ and $2(c)$. 


\section{Discussion}

Protection from swine dysentery after vaccination with whole cell preparations (based mainly on LPS) is relatively poor (Fernie et al., 1983; Glock et al., 1978; Lysons \& Burrows, 1989) and partially serotype specific (Joens et al., 1983). In order to circumvent these drawbacks, a subunit vaccine might be needed, based on possible virulence factors other than LPS, which induces protection against challenge with all homologous and heterologous types. In the case of another bacterium, Actinobacillus pleuropneumoniae, the haemolysin/cytotoxin determinant was chosen for this purpose (Bosch et al., 1990; Frey \& Nicolet, 1990; Smit et al., 1990). Likewise, we have also focused on haemolysin(s) as well as on the flagella as possible virulence factors of $S$. hyodysenteriae. To confirm that these recombinant DNA vaccines will provide universal protection, the genotypes of prevalent strains rather than serotypes are important (Ellis et al., 1991; Thiermann \& Ellis, 1985).

Combs et al. (1989) were able to distinguish REA patterns of strains within serotypes of $S$. hyodysenteriae. They therefore suggested that serotyping may not give an accurate reflection of the number of different pathogenic clones within an area. In the present study two ATCC strains belonging to the same serotype were found to have different REA patterns also. Thiermann \& Ellis (1985) could, in this way, distinguish genotypes with different pathogenicity within Leptospira interrogans serogroup Sejroe serovar hardjo: hardjo-bovis and hardjo-prajitno. This had consequences for vaccine components, as the vaccine so far used in North America contained reference strain hardjo-prajitno, while all isolates examined in that study, belonged to the hardjobovis genotype.

In the present study the Dutch $S$. hyodysenteriae isolates could be divided in two main REA patterns (Table 1). The $S$. hyodysenteriae reference strains all had different REA patterns (Fig. 2a). This is in accordance with the results of Combs et al. (1989), who found that REA patterns of all local (West Australian) strains were different from those of overseas strains (including five reference strains used in the present study: $B 78^{\mathrm{T}}, \mathrm{B} 234^{\mathrm{T}}$, $B 204^{\mathrm{T}}, \mathrm{B} 169$ and $\mathrm{A} 1$ ). Moreover, the REA patterns of the five above-mentioned reference strains were all distinct in both our study and that of Combs et al. (1989), although different restriction enzymes were used. The non-pathogenic Dutch Serpulina strains and $S$. innocens showed an extensive variety of REA patterns, all different from the REA patterns of the $S$. hyodysenteriae strains (Table 1).

DNA hybridization with defined DNA probes has been used to demonstrate genetic relationships and differences within leptospires, Borrelia burgdorferi and
Mycobacterium paratuberculosis (Collins et al., 1990; van Eys et al., 1991; LeFebvre et al., 1989). Van Eys et al. (1991) used defined DNA probes to demonstrate four subgroups with extensive genomic homology within serogroup Sejroe of $L$. interrogans. Strains within REA patterns could be distinguished by hybridization, while a number of serovars outside serogroup Sejroe also showed homology with these subgroups.

In the present study two defined DNA probes of $S$. hyodysenteriae (Fla and Tly) were used for Southern analysis. Upon hybridization with the Fla probe all $S$. hyodysenteriae isolates fell into hybridization patterns A and B. Hybridization with the Fla probe did not distinguish strains within REA patterns, but showed homologies between strains of different REA patterns. Upon hybridization with the Fla probe, all nonpathogenic strains hybridized weakly with one band of varying size, confirming the large heterogeneity of these strains.

Upon hybridization with the $S$. hyodysenteriae Tly probe, all $S$. hyodysenteriae isolates fell into a single pattern (Table 1, Figs $1 c$ and $2 c$ ). This is in accordance with the results of Muir et al. (1992), who did Southern hybridization of the identical reference strains of $S$. hyodysenteriae with the same Tly probe to examine the copy number of a haemolysin gene. None of the nonpathogenic Dutch Serpulina strains nor $S$. innocens hybridized with this probe. This indicated extensive genomic homology within all tested $S$. hyodysenteriae strains. Under these hybridization conditions no genomic relationship was found between the tested $S$. hyodysenteriae and non-pathogenic Serpulina strains.

We have called the weakly haemolytic Dutch porcine spirochaetal strains non-pathogenic Serpulina. Although some strains could belong to the non-pathogenic $S$. innocens group, it seems more likely that these strains belong to more than one species. The variation observed in REA pattern and hybridization pattern to the Fla probe of these non-pathogenic spirochaetes was in accordance with the serological variation of nonpathogenic spirochaetes (Adachi et al., 1981; Lemcke \& Burrows, 1979). Lymbery et al. (1990) also identified three genetically different groups among 10 isolates of non-pathogenic spirochaetes.

In view of the observed homologies, we suggest that challenge studies with swine dysentery vaccines based on recombinant DNA technology can be limited to a small number of strains. Depending on the component(s), either haemolysin and/or flagellar proteins, challenge studies need to be done with one or two genotypes only.

We thank Dr S. Muir for providing a haemolytic $S$. hyodysenteriae clone; Dr J. G. Kusters and Ing. K. A. Zwaagstra for critical comments; the Dutch Animal Health Centres and the Central Veterinary Institute for providing isolates and/or samples. 


\section{References}

Adachi, Y., Kume, T., Yamamoto, S. \& Watase, H. (1981). Comparison of antigenic properties among several strains of weak beta-hemolytic treponeme isolated from swine and a dog. Zentralblatt für Bakteriologie, Mikrobiologie und Hygiene (Abt. I, Originale A) 248, 541-547.

van den Bosch, J. F., Pennings, A. M. M. A., Cuijpers, M. E. C. M., Pubben, A. N. B., van Vugt, F. G. A. \& van Der Linden, M. F. I. (1990). Heterologous protection induced by an A. pleuropneumoniae subunit vaccine. Proceedings of the International Pig Veterinary Society Congress Lausanne, 11.

Boyden, D. A., Albert, F. G. \& Robinson, C. S. (1989). Cloning and characterization of Treponema hyodysenteriae antigens and protection in a CF-1 mouse model by immunization with a cloned endoflagellar antigen. Infection and Immunity 57, 3808-3815.

Collins, D. M., Gabric, D. M. \& DE LISLE, G. W. (1990). Identification of two groups of Mycobacterium paratuberculosis strains by restriction endonuclease analysis and DNA hybridization. Journal of Clinical Microbiology 28, 1591-1596.

Combs, B., Hampson, D. J., MHOMa, J. R. L. \& Buddle, J. R. (1989). Typing of Treponema hyodysenteriae by restriction endonuclease analysis. Veterinary Microbiology 19, 351-359.

Ellis, W. A., Montgomery, J. M. \& ThiermanN, A. B. (1991). Restriction endonuclease analysis as a taxonomic tool in the study of pig isolates belonging to the Australis serogroup of Leptospira interrogans. Journal of Clinical Microbiology 29, 957-961.

VAN Eys, G. J. J. M., Gerritsen, M. J., Korver, H., Schoone, G. J., KroON, C. C. M. \& Terpstra, W. J. (1991). Characterization of serovars of the genus Leptospira by DNA hybridization with hardjobovis and icterohaemorrhagiae recombinant probes with special attention to serogroup Sejroe. Journal of Clinical Microbiology 29, 1042-1048.

Fernie, D. S., Ripley, P. H. \& Walker, P. D. (1983). Swine dysentery: protection against experimental challenge following single dose parenteral immunization with inactive Treponema hyodysenteriae. Research in Veterinary Science 35, 217-221.

FREY, J. \& NicoleT, J. (1990). Immunogenic properties of hemolysin I of Actinobacillus pleuropneumoniae. Proceedings of the International Pig Veterinary Society Congress Lausanne, 7.

Glock, R. D., Schwartz, K. J. \& Harris, D. L. (1978). Parenteral immunization of pigs against infection with Treponema hyodysenteriae. American Journal of Veterinary Research 39, 639-642.

Harris, D. L., Glock, R. D., Christensen, C. R. \& Kinyon, J. M. (1972). Swine dysentery. I. Inoculation of pigs with Treponema hyodysenteriae (new species) and reproduction of the disease. Veterinary Medicine and Small Animal Clinician 67, 61-64.

ter HuUrne, A. A. H. M., van Houten, M., Muir, M., Kusters, J. G., VAN DER ZEIJST, B. A. M. \& GAASTRA, W. (1992). Inactivation of a Serpula (Treponema) hyodysenteriae hemolysin gene by homologous recombination: importance of this hemolysin in pathogenesis of S. hyodysenteriae in mice. FEMS Microbiology Letters 92, 109-114.

JoEns, L. A., HARRIS, D. L. \& BAUM, D. H. (1979). Immunity to swine dysentery in recovered pigs. American Journal of Veterinary Research 40, 1352-1354.

Joens, L. A., Whipp, S. C., Glock, R. D. \& Nuessen, M. E. (1983). Serotype-specific protection against Treponema hyodysenteriae infection in ligated colonic loops of pigs recovered from swine dysentery. Infection and Immunity 39, 460-462.

KinYon, J. M. \& HARRIS, D. L. (1979). Treponema innocens, a new species of intestinal bacteria, and emended description of the type strain of Treponema hyodysenteriae Harris et al. International Journal of Systematic Bacteriology 29, 102-109.
KINYON, J. M., HARRIS, D. L. \& GLoCK, R. D. (1977). Enteropathogenicity of various isolates of Treponema hyodysenteriae. Infection and Immunity 15, 638-646.

KoOpMan, M. B. H., De Leeuw, O. S., van DeR ZeiJst, B. A. M. \& Kusters, J. G. (1992). Cloning and DNA sequence analysis of a Serpula (Treponema) hyodysenteriae gene encoding a periplasmic flagellar sheath protein. Infection and Immunity 60, 2920-2925.

KUNKLE, R. A. \& KINYON, J. M. (1988). Improved selective medium for the isolation of Treponema hyodysenteriae. Journal of Clinical Microbiology 26, 2357-2360.

LeFebvre, R. B., Perng, G. C. \& Johnson, R. C. (1989). Characterization of Borrelia burgdorferi isolates by restriction endonuclease analysis and DNA hybridization. Journal of Clinical Microbiology 27, 636-639.

LEMCKe, R. M. \& BURRows, M. R. (1979). A disc growth-inhibition test for differentiating Treponema hyodysenteriae from other spirochaetes. Veterinary Record 104, 548-551.

Lymbery, A. J., Hampson, D. J., Hopkins, R. M., Combs, B. \& Mнома, J. R. L. (1990). Multilocus enzyme electrophoresis for identification and typing of Treponema hyodysenteriae and related spirochaetes. Veterinary Microbiology 22, 89-99.

Lysons, R. J. \& BURRows, M. R. (1989). Stimulation of a protective immunity to swine dysentery by a combination of intramuscular and live oral vaccines. Proceedings of the Congress on Biology and Pathogenicity of Treponemes, Birmingham.

Lysons, R. J., Kent, K. A., Bland, A. P., Sellwood, R., Robinson, W. F. \& Frost, A. J. (1991). A cytotoxic haemolysin from Treponema hyodysenteriae - a probable virulence determinant in swine dysentery. Journal of Medical Microbiology 34, 97-102.

MAPOTHER, M. E. \& JOENS, L. A. (1985). New serotypes of Treponema hyodysenteriae. Journal of Clinical Microbiology 22, 161-164.

Muir, S., Koopman, M. B. H., LibBy, S. J., Joens, L. A., HefFron, F. \& KuSTERS, J. G. (1992). Cloning and expression of a Treponema hyodysenteriae hemolysin gene. Infection and Immunity 60, 529-535.

Olson, L. D. (1986). Probable elimination of swine dysentery after feeding ronidazole, carbadox or lincomycin and verification by feeding sodium arsanilate. Canadian Journal of Veterinary Research 50, 365-368.

SambrooK, J., Fritsch, E. F. \& Maniatis, T. (1989). Molecular Cloning, a Laboratory Manual, 2nd edn. Cold Spring Harbor, NY: Cold Spring Harbor Laboratory.

SMIT, H. F. \& JONGERIUS, J. M. (1982). Swine dysentery diagnosis: to isolate or to fluoresce? Veterinary Record 111, 343.

Smit, M., BriaIRE, J. \& KAMP, E. (1990). Characterization of the hemolysin/cytotoxin determinant of Actinobacillus pleuropneumoniae serotype 9. Proceedings of the International Pig Veterinary Society Congress Lausanne, 21.

Songer, J. G., KinYon, J. M. \& HARris, D. L. (1976). Selective medium for isolation of Treponema hyodysenteriae. Journal of Clinical Microbiology 4, 57-60.

TAYLOR, D. J. \& AleXander, T. J. L. (1971). The production of dysentery in swine by feeding cultures containing a spirochaete. British Veterinary Journal 127, 58-61.

ThiermanN, A. B. \& Ellis, W. E. (1985). Identification of leptospires of veterinary importance by restriction endonuclease analysis. In The Present State of Leptospirosis Diagnosis and Control, pp. 91-104. Edited by W. A. Ellis \& T. W. A. Little: Dordrecht: Martinus Nijhof.

Thiermann, A. B., Handsaker, A. L., Foley, J. W., White, F. H. \& Kingscote, B. F. (1986). Reclassification of North American leptospiral isolates belonging to serogroups Mini and Sejroe by restriction endonuclease analysis. American Journal of Veterinary Research 47, 61-66. 